\title{
Exploring the Triple Reciprocity Nature of Organizational Value Cocreation Behavior Using Multicriteria Decision Making Analysis
}

\author{
Huan-Ming Chuang, ${ }^{1}$ Chyuan-Yuh Lin, ${ }^{1}$ and You-Shyang Chen ${ }^{2}$ \\ ${ }^{1}$ Department of Information Management, National Yunlin University of Science and Technology, 123 University Road, \\ Section 3, Douliou, Yunlin 64002, Taiwan \\ ${ }^{2}$ Department of Information Management, Hwa Hsia University of Technology, 111 Gong Jhuan Road, Chung Ho District, \\ New Taipei City 235, Taiwan \\ Correspondence should be addressed to You-Shyang Chen; g9523804@yuntech.edu.tw
}

Received 24 October 2014; Accepted 20 December 2014

Academic Editor: Neil Y. Yen

Copyright (C) 2015 Huan-Ming Chuang et al. This is an open access article distributed under the Creative Commons Attribution License, which permits unrestricted use, distribution, and reproduction in any medium, provided the original work is properly cited.

Service-dominant (S-D) logic is a service science framework that is more robust than the traditional goods-dominant (G-D) logic. It emphasizes the importance of operant resources and value Cocreation. This study employs social cognitive theory to explore the triple reciprocity of organizational value Cocreation behavior. Further, this study uses DEMATEL-based ANP to examine the dynamic nature of organizational value Cocreation behavior. The major results of this study can be described as follows. First, the triadic reciprocity of personal, environmental, and behavioral factors are validated. Second, the dominant influencing trends are clearly identified. From a dimensional point of view, environmental factors affect personal factors and behavioral factors, and personal factors affect behavioral factors. Similarly, in terms of organizational value Cocreation behavior, organizational identification affects altruistic behavior and knowledge-sharing behavior, and altruistic behavior affects knowledgesharing behavior. These findings may provide helpful guidance in effectively promoting organizational value cocreation behavior, enabling organizations to leverage operant resources to their maximum potential.

\section{Introduction}

Both academics and practitioners have noticed the important relationships between service, performance, and competitive advantage. The link between superior performance and competitive advantage has been well validated. However, according to Lusch et al. [1], there is little evidence regarding significant increases in service quality. Therefore, they posit that a relatively new perspective, named service-dominant (SD) logic, is needed to view markets, exchange, and competing through the lens of service.

$\mathrm{S}$-D logic is a more robust framework for service science than the traditional goods-dominant (G-D) logic is [2], with the following important tenets: (1) service is conceptualized as a process rather than a unit of output; (2) service focuses on dynamic (or operant) resources, such as knowledge and skills, rather than static (or operand) resources, such as natural resources; and (3) service looks upon value as a collaborative process between stakeholders (i.e., providers and customers), not a unilateral one where producers create value and then deliver it to customers.

Under this background, organizational performance and competitive advantage hinge on the effectiveness of the value cocreation network formed by participatory employees. Because knowledge and skills are important operant resources under S-D logic, knowledge-sharing behavior is an essential value cocreation activity that deserves deep examination. Knowledge sharing between employees and within 
and across teams allows organizations to exploit knowledgerelated resources $[3,4]$ to create and sustain competitive advantages in a highly competitive and dynamic economy $[4,5]$. In order to reap these benefits, many organizations have invested tremendous resources and efforts in knowledge management initiatives. However, most of these investments have not produced desirable outcomes [6].

According to Davenport and Prusak [4], when implementing knowledge management initiatives, organizations usually consider their technology infrastructure to be the most important component. Therefore, they tend to focus only on the technological aspects of the system. However, because organizational value cocreation behavior (i.e., knowledge sharing) is an inherently social process, its ultimate success involves social and environmental factors in addition to technology investment. Consequently, a socialtechnical approach can shed light on the way technology is adapted and used in an organization [7].

As a result, this study follows a social-technical approach, specifically social cognitive theory. First, we identify important elements related to the environmental, personal, and behavioral dimensions through a literature review. Then, appropriate tools from multicriteria decision making $(\mathrm{MCDM})$, such as decision-making trial and evaluation laboratory (DEMATEL) and analytical network process (ANP), are applied to explore the triple reciprocity of value cocreation behavior. These tools are particularly valuable because they rely on extensive pairwise comparisons among system elements; no prior assumptions about their relationships are needed. Subsequently, the final influence patterns (directions and degrees) are objectively derived by mathematic calculations instead of subjective judgments. In this way, the present study can contribute insightful and complementary findings to this research field.

\section{Theoretical Background}

This study employs social cognitive theory to explore the triple reciprocity of organizational value cocreation behavior. Related theories are discussed below.

2.1. Social Cognitive Theory. Social cognitive theory (SCT) is a widely accepted, as well as empirically validated, model of individual behavior [8]. It is based on the premise that cognitive and other personal factors, environmental influences, and behavior are reciprocally determined, as shown in Figure 1 [9].

In general, personal factors include personality and demographic characteristics, and environmental influences come from social pressure or unique situational characteristics. According to SCT, individuals choose the environments they are involved in and are influenced by the environment incidentally. Furthermore, cognitive and personal factors are determined, as well as reshaped, by behavior. Finally, in a given situation, behavior is affected by environmental and/or situational characteristics, which are in turn influenced by behavior. Bandura denotes the nature of these relationships

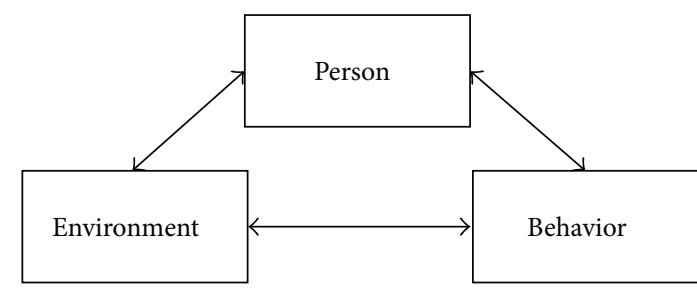

FIGURE 1: Interaction between the environment, individual, and behavior.

as "triadic reciprocity" [10]. This study concerns dynamic interactions in the context of organizational value cocreation.

2.2. Organizational Value Cocreation Behavior (Behavior Dimensions of SCT). This study explores organizational value cocreation from the perspective of organizational citizenship behavior (OCB), including organizational identification, altruistic behavior, and knowledge-sharing behavior.

Davenport and Prusak [4] argued that it is often unnatural for people to engage in knowledge sharing, as they consider their knowledge to be valuable and important. Thus, individuals may have a natural tendency to withhold their knowledge from others. Moreover, research has addressed the challenge that knowledge sharing rarely occurs spontaneously [11]. Therefore, it is beneficial to explore how voluntary knowledge sharing can be facilitated effectively.

Clearly, active knowledge sharing requires that individual members be willing to provide spontaneous assistance without assurance of reciprocation, which is strongly related to OCB. Organ [12] defined OCB as work-related behavior that is discretionary, not related to the formal organizational reward system, and, in aggregate, promotes the effective functioning of the organization.

Specifically, Organ and Konovsky [13] defined the following five types of OCB:

(1) altruism: voluntary actions that help another person with a work-related problem,

(2) conscientiousness: going well beyond the required levels of responsibility,

(3) civic virtue: responsible and constructive involvement in the political process of an organization,

(4) sportsmanship: tolerating the inevitable inconvenience and impositions of work without complaining,

(5) courtesy: providing advance notice to people who need such information.

In a knowledge management context, sharing knowledge with others without an expectation of reciprocation represents altruistic behavior. Further, when sharing knowledge, the contributors participate conscientiously and actively (courtesy) with civic virtue, and they tolerate the efforts required to share their resources (sportsmanship). Thus, knowledge-sharing behavior can be viewed as a typical OCB.

William and Anderson [14] further divided OCB into two major dimensions: (1) behaviors directed at specific 
individuals in the organization, such as courtesy and altruism (OCB-I, I: individual) and (2) behaviors concerned with benefiting the organization as a whole, such as conscientiousness, sportsmanship, and civic virtue (OCB-O, O: organization). OCB-I refers to the behaviors that benefit specific individuals within an organization first and then contribute indirectly to organizational effectiveness $[14,15]$. OCB-I involves voluntarily helping to solve work-related problems. In contrast, OCB$O$ refers to behaviors that benefit the organization in general, without actions aimed specifically toward any organizational member. Podsakoff et al. [16] labeled OCB-O as a form of organizational compliance involving an internalization of a company's rules and policies. This study follows this classification of OCB and adopts organizational identification and altruistic behavior to represent OCB-O and OCB-I, respectively. Table 1 further elucidates the organizational value cocreation behaviors referenced in this study.

\subsection{Organizational Climate (Environment Dimensions of} $S C T)$. Organizational climate refers to the perceptions and feelings of organizational members regarding their work environment [17]. It is multidimensional in nature and is assumed to influence personal motivation and behavior [1820]. For example, Schulte and Ostroff [21] maintained that organizational climate plays an important role in understanding organizational members' attitudes. Moreover, they proved that individuals' evaluations of the climate are positively related to their attitude. Specifically, the more positive the perception of the organizational climate, the more energetic the collective attitude.

Different aspects of organizational climate have been identified as critical drivers of knowledge sharing, such as top management support [11], employee involvement [22, 23], stimulus to develop new ideas [24], an open and freely expressive atmosphere where information keeps flowing [25, 26], communication network [27, 28], and reward systems linked to knowledge sharing [29].

In line with previous research [24, 30, 31], we identify four subfactors of organizational climate, as identified in Table 2.

\subsection{Self-Efficacy and Outcome Expectations (Personal Dimen-} sions of SCT). In terms of personal factors, SCT emphasizes two sets of expectations as the major cognitive forces guiding behavior. The first set of expectations relates to outcome expectations, and the second set encompasses self-efficacy $[10,32,33]$. Outcome expectations refer to the judgment of likely consequences of specific behavior. Outcome expectations may be personal, such as a sense of satisfaction or happiness, or team-related, such as improved project performance. Meanwhile, self-efficacy is the belief that one possesses the skills and abilities to successfully accomplish a specific task [34].

Without incentives, people are seldom willing to spend their time and effort to perform specific behaviors. Therefore, outcome expectations play an important role in inducing desired behaviors. According to economic exchange theory, an individual's behaviors are strongly motivated by selfinterest (i.e., positive personal expectations). Furthermore, based on social exchange theory, if employees believe they can improve their relationship with other employees by offering knowledge (i.e., positive team-related outcome expectations), they develop a more positive attitude toward knowledge sharing [35].

Though positive outcome expectations are essential for producing actual behavior, they must be supplemented by positive self-efficacy. Perceived self-efficacy plays an important role in one's choices about which behaviors to undertake and in the effort and persistence one invests in overcoming obstacles to the performance of those behaviors $[10,32,36$, 37]. People who have higher self-efficacy are more likely to perform related behaviors than are those with lower selfefficacy. As a result, Bandura [32] posited that self-efficacy ultimately leads to the mastery of behaviors.

In the context of knowledge sharing, self-efficacy plays a particularly dominant role $[38,39]$. It has a direct impact on outcome expectations [32], and individuals with positive outcome expectations are more likely to share their knowledge [39]. Table 3 summarizes the aspects of self-efficacy and outcome expectations referenced in this study.

Finally, we investigate dynamic interactions in an organizational value cocreation context. With the support of the previous literature, this study utilizes social cognitive theory to explore the triple reciprocity of organizational value cocreation behavior. Therefore, this study proposes the research framework shown in Figure 2. Further, this study employs DEMATEL-based ANP to examine the dynamic nature of organizational value cocreation behavior.

\section{Building a DANP Model for Exploring the Dynamics of Knowledge-Sharing Behavior}

This study applies DEMATEL-based ANP (DANP) to validate the proposed research framework. DANP can identify the interdependence among various dimensions and criteria. Figure 3 provides an illustration of DANP.

3.1. DEMATEL. Originating from the Geneva Research Centre of the Battelle Memorial Institute, the DEMATEL approach is a mathematical procedure designed to deal with important issues of world societies [40]. The DEMATEL possesses some excellent features. For example, it is based on matrices to represent the contextual relation as well as strength of influence of the elements of the target system. It can also convert the cause-effect relationship of elements into visible structural models.

Due to its practical benefits, the DEMATEL has been widely applied in various fields, such as marketing [41], education $[42,43]$, investment [44], and supply chain management [45].

The steps for building an impact-relation map (IRM) using a DEMATEL technique (Steps 1-3) and finding influential weights using an ANP technique (Steps 4-6) are summarized below. 
TABLE 1: Examples of organizational value cocreation behaviors.

\begin{tabular}{ll}
\hline Behavioral dimensions & Examples \\
\hline & (1) I will share my work reports and official documents with other team members more frequently in the \\
future. \\
Knowledge-sharing \\
(2) I intend to share my experience or know-how from work with other team members more frequently in \\
the future. \\
(3) I try to share my expertise from my education or training with other team members in an effective way. \\
(1) I make every effort to safeguard the image of my company. \\
(2) I make every effort to demonstrate the strength of my company. \\
(3) I put forward good suggestions voluntarily to the members of my company. \\
(4) I participate in the activities of my company with a positive attitude. \\
identification \\
(1) Rather than evading assigned tasks, I willingly take on new or challenging tasks. \\
(2) I help members to resolve conflicts and misunderstandings to maintain a harmonious company. \\
(3) I am able to maintain good relations with my team members. \\
(4) I communicate with my team members actively while carrying out communal tasks.
\end{tabular}

Reference: [64, 65].

TABLE 2: Four subfactors of organizational climate.

\begin{tabular}{ll}
\hline $\begin{array}{l}\text { Environment } \\
\text { dimensions }\end{array}$ & Examples \\
\hline $\begin{array}{l}\text { Top } \\
\text { management } \\
\text { support. }\end{array}$ & $\begin{array}{l}\text { Top management clearly supports the role of } \\
\text { knowledge sharing. }\end{array}$ \\
$\begin{array}{l}\text { Open } \\
\text { communication }\end{array}$ & $\begin{array}{l}\text { Employees are encouraged to interact with } \\
\text { their colleagues. }\end{array}$ \\
Innovativeness & $\begin{array}{l}\text { Employees are encouraged to suggest ideas for } \\
\text { new opportunities. } \\
\text { Organization provides a reward system to } \\
\text { Reward system }\end{array}$ \\
\hline
\end{tabular}

Reference: [24, 30, 31].

TABLE 3: Definitions and examples of self-efficacy and outcome expectations.

\begin{tabular}{|c|c|}
\hline Personal dimensions & Examples \\
\hline $\begin{array}{l}\text { Self-efficacy: the confidence in one's ability } \\
\text { to provide knowledge that is valuable to the } \\
\text { work group. }\end{array}$ & $\begin{array}{l}\text { I have confidence in my ability to } \\
\text { (1) provide knowledge that people I work with consider valuable, } \\
\text { (2) provide knowledge that people I work with consider informative, } \\
\text { (3) provide knowledge that people I work with consider helpful, } \\
\text { (4) be well informed in order to provide valuable knowledge, } \\
\text { (5) have the expertise needed to provide knowledge. }\end{array}$ \\
\hline $\begin{array}{l}\text { Personal outcome expectations: the } \\
\text { knowledge contributor's judgment of the } \\
\text { likely consequences that his or her } \\
\text { knowledge sharing may bring to himself or } \\
\text { herself. }\end{array}$ & $\begin{array}{l}\text { Sharing my knowledge will } \\
\text { (1) help me make friends with other members in the work group, } \\
\text { (2) give me a feeling of happiness, } \\
\text { (3) build my reputation in my work group, } \\
\text { (4) give me a sense of accomplishment, } \\
\text { (5) strengthen the tie between me and others in the work group, } \\
\text { (6) enable me to gain better cooperation in the future from outstanding members in } \\
\text { the work group. }\end{array}$ \\
\hline $\begin{array}{l}\text { Team outcome expectation: the knowledge } \\
\text { contributor's judgment of the likely } \\
\text { consequences that his or her knowledge } \\
\text { sharing may bring to the team. }\end{array}$ & $\begin{array}{l}\text { Sharing my knowledge will help my work group } \\
\text { (1) be more capable of meeting project goals, } \\
\text { (2) produce a greater amount of knowledge, } \\
\text { (3) produce a higher quality of knowledge, } \\
\text { (4) adhere more closely to project schedules, } \\
\text { (5) have higher operational efficiency, } \\
\text { (6) have higher operational speed. }\end{array}$ \\
\hline
\end{tabular}

Reference: [38, 39]. 


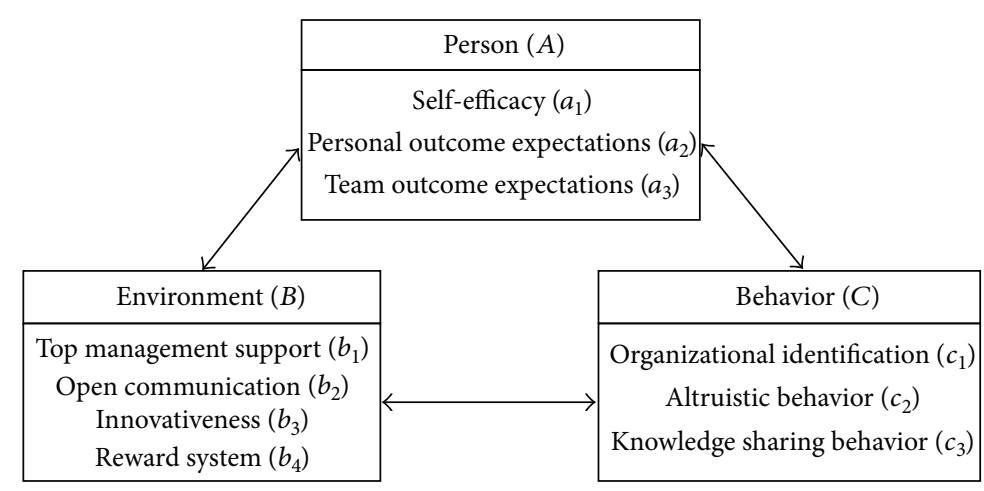

FIGURE 2: Research framework of this study.

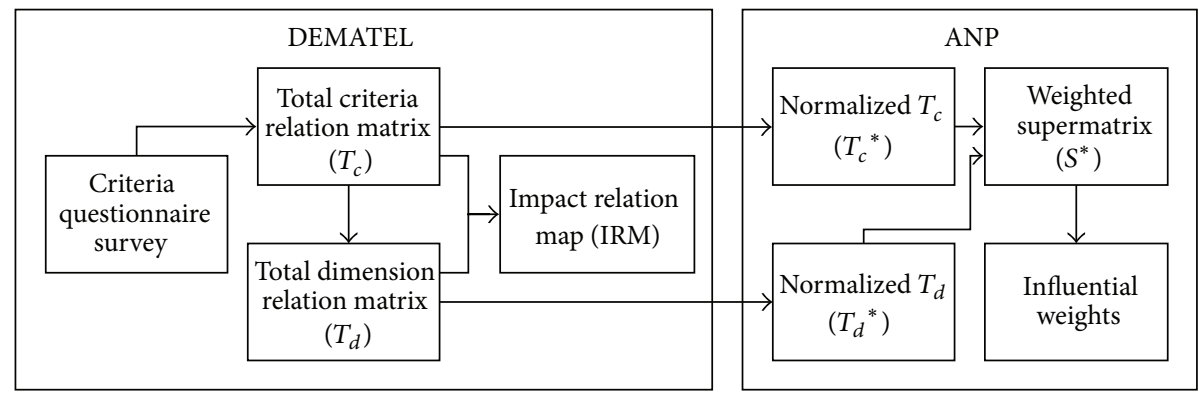

FIgURE 3: DEMATEL-based ANP.

Step 1 (generate the initial direct-relation matrix). Acquire the assessments about the direct influence between each pair of elements from a committee of experts. The pairwise comparison is designated by five levels- $0,1,2,3$, and 4-to represent "no influence," "very low influence," "low influence," "high influence," and "very high influence," respectively. The initial direct-relation matrix $A$ is an $n \times n$ matrix in which $a_{i j}$ is denoted as the degree to which the element $i$ affects the element $j$; that is, $A=\left[a_{i j}\right]_{n \times n}$.

Step 2 (normalize the initial relation matrix to attain total-relation matrices). The normalized direct-relation matrix $X=$ $\left[x_{i j}\right]$ can be obtained through

$$
\begin{gathered}
s=\max _{i j}\left[\max _{1 \leq i \leq n} \sum_{j=1}^{n} a_{i j}, \max _{1 \leq j \leq n} \sum_{i=1}^{n} a_{i j}\right], \\
X=\frac{1}{s} A .
\end{gathered}
$$

Here, (1) represents the maximum values of the sums of all the rows and the sums of all the columns. Equation (2) represents the normalized initial direct-relation matrix. All elements in matrix $X$ are complying with $0 \leq x_{i j} \leq 10$, and all principal diagonal elements are equal to 0 . Thus, the total relation matrix, $T$, can be obtained by using the following numerical calculation:

$$
\begin{gathered}
T=X+X^{2}+\cdots+X^{p}=X \times(1-X)^{-1}=\left[x_{i j}\right]_{n \times n} \\
p \rightarrow \infty \\
T=\left[t_{i j}\right]_{n \times n}, \quad i, j=1,2, \ldots, n .
\end{gathered}
$$

Here, $I$ is the identity matrix and $p$ represents the power. Hence, when $p$ tends to infinity, the matrix $X$ will converge.

The total relation matrix produced by the DEMATEL approach is based on the comparisons among criteria. Therefore, it can be renamed as a total criteria relation matrix $\left(T_{c}=\left[T_{c}^{i j}\right]_{n \times n}\right)$, as shown in (4), with $m$ dimensions and $n_{1}$ to $n_{m}$ criteria each. $D_{m}$ denotes the $m_{t h}$ dimension; $C_{n m}$ represents the $m_{t h}$ criteria in the $n_{t h}$ dimension; and $T_{c}^{i j}$ is the principle eigenvector of the influences of the elements in the $i_{\text {th }}$ dimension, as compared to the $i_{\text {th }}$ dimension: 


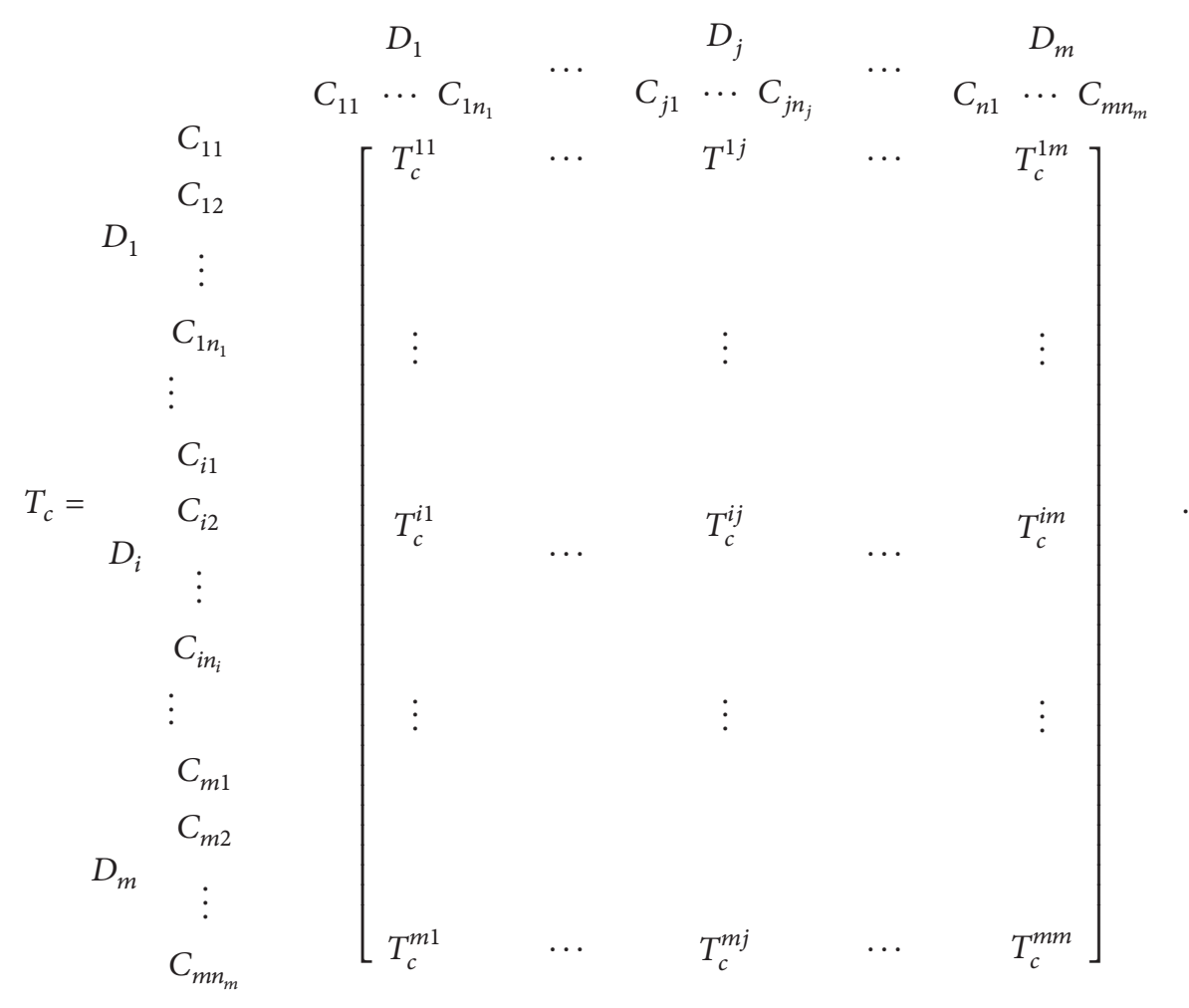

Based on $T_{c}$, the total dimensions relation matrix $T_{d}$ can be generated from the total criteria matrix using the following, where $t_{d}^{i j}$ is the average of elements of matrix $T_{c}^{i j}$ :

$$
T_{d}=\left[\begin{array}{ccccc}
t_{d}^{11} & \cdots & t_{d}^{1 j} & \cdots & t_{d}^{1 m} \\
\vdots & & \vdots & & \vdots \\
t_{d}^{i 1} & \cdots & t_{d}^{i j} & \cdots & t_{d}^{i m} \\
\vdots & & \vdots & & \vdots \\
t_{d}^{m 1} & \cdots & t_{d}^{m j} & \cdots & t_{d}^{m m}
\end{array}\right] .
$$

Step 3 (produce the IRM). The IRM of $T_{c}$ and $T_{d}$ is established via the vectors $r$ and $s$, the sums of rows and columns, respectively, which are obtained by

$$
\begin{aligned}
& r=\left[r_{i}\right]_{n \times 1}=\left[\sum_{j=1}^{n} t_{i j}\right]_{n \times 1} \\
& s=\left[s_{j}\right]_{n \times 1}=\left[\sum_{i=1}^{n} t_{i j}\right]_{1 \times n}^{\prime} .
\end{aligned}
$$

$r_{i}$ denotes the sum of the $i_{\text {th }}$ row, representing all influences of criteria (or dimensions) on other criteria (or dimensions). Moreover, $s_{j}$ denotes the sum of the $i_{t h}$ column of matrix $T_{c}$ (or $T_{d}$ ), meaning the total impact that criterion (or dimension) $j$ gets from other criteria (or dimensions).

The IRM can be constructed by mapping the dataset of $\left(r_{i}+s_{j}, r_{i}-s_{j}\right)$. The horizontal axis vector $\left(r_{i}+s_{j}\right)$, named "prominence," is produced by adding $r_{i}$ to $s_{j}$, which shows the importance of the element. Similarly, the vertical axis $\left(r_{i}-\right.$ $s_{j}$ ), named "relation," is produced by subtracting $r_{i}$ from $s_{j}$. Generally, when $\left(r_{i}-s_{j}\right)$ is positive, the element belongs to the cause group; otherwise, the element belongs to the effect group [46, 47].

After calculating the means of $\left(r_{i}+s_{j}\right)$ and $\left(r_{i}-s_{j}\right)$, the IRM can be divided into four quadrants. Elements in quadrant I have both high prominence and relation, which means they have the highest level of interaction influence on other elements; thus, they can be identified as driving factors. Elements in quadrant II have low prominence but high relation and can be identified as voluntary factors. Elements in quadrant III have both low prominence and relation, and they are relatively disconnected from the system. Finally, the elements in quadrant IV have high prominence and low relation, which means they are important items affected by other elements [48].

3.2. ANP. Saaty [49] established the analytical network process (ANP) as a way to determine complicated nonlinear network relationships. This method addressed the limitations of the analytical hierarchy process (AHP), which hypothesizes that all factors of indices under each level of the framework possess mutual independence [50]. Nevertheless, the ANP survey questionnaire would be too laborious to fill out $[51,52]$. To solve this problem, we based the questionnaire on 
the total criteria matrix and total dimensions matrix generated by DEMATEL. This enabled us to conduct further procedures required by ANP to deal with the problems of dependence and feedback among criteria, as described in the following steps.

Step 4 (normalize the total criteria relation matrix). Using the total degree of effect and influence of the dimensions, the total criteria relation matrix $T_{c}$ can be normalized to obtain $T_{c}^{*}$, as shown in

$$
\begin{aligned}
& d_{c i}^{11}=\sum_{j=1}^{m_{1}} t_{i j}^{11}, \quad i=1,2, \ldots, m_{1}, \\
& T_{c *}^{11}=\left[\begin{array}{ccccc}
\frac{t_{c 11}^{11}}{d_{c 1}^{11}} & \cdots & \frac{t_{c 1 j}^{11}}{d_{c 1}^{11}} & \cdots & \frac{t_{c 1 n_{1}}^{11}}{d_{c 1}^{11}} \\
\vdots & & \vdots & \vdots \\
\frac{t_{c i 1}^{11}}{d_{c i}^{11}} & \cdots & \frac{t_{c i j}^{11}}{d_{c i}^{11}} & \cdots & \frac{t_{c i n_{1}}^{11}}{d_{c i}^{11}} \\
\vdots & & \vdots & & \vdots \\
\frac{t_{c n_{1} 1}^{11}}{d_{c n_{1}}^{11}} & \cdots & \frac{t_{c n_{1 j}}^{11}}{d_{c n_{1}}^{11}} & \cdots & \frac{t_{c n_{1} n_{1}}^{11}}{d_{c n_{1}}^{11}}
\end{array}\right] \\
& =\left[\begin{array}{ccccc}
t_{c 11 *}^{11} & \cdots & t_{c 1 j *}^{11} & \cdots & t_{c 1 n_{1} *}^{11} \\
\vdots & & \vdots & & \vdots \\
t_{c i 1 *}^{11} & \cdots & t_{c i j *}^{11} & \cdots & t_{c i n_{1} *}^{11} \\
\vdots & & \vdots & & \vdots \\
t_{c n_{1} 1 *}^{11} & \cdots & t_{c n_{1} 1 *}^{11} & \cdots & t_{c n_{1} n_{1} *}^{11}
\end{array}\right], \\
& T_{c}^{*}=\left[\begin{array}{ccccc}
T_{c *}^{11} & \cdots & T_{c *}^{1 j} & \cdots & T_{c *}^{1 m} \\
\vdots & & \vdots & & \vdots \\
T_{c *}^{i 1} & \cdots & T_{c *}^{i j} & \cdots & T_{c *}^{i m} \\
\vdots & & \vdots & & \vdots \\
T_{c *}^{m 1} & \cdots & T_{c *}^{m j} & \cdots & T_{c *}^{m m}
\end{array}\right] .
\end{aligned}
$$

Step 5 (normalize the total dimensions relation matrix). The total dimension matrix $T_{d}$ can be normalized by (8) to obtain $T_{d}^{*}$, representing the weights of dimensions:

$$
t_{d}^{1}=\sum_{j=1}^{m} t_{d}^{i j},
$$

$$
\begin{aligned}
& T_{d}^{*}=\left[\begin{array}{ccccc}
\frac{t_{d}^{11}}{t_{d}^{1}} & \cdots & \frac{t_{d}^{1 j}}{t_{d}^{1}} & \cdots & \frac{t_{d}^{1 m}}{t_{d}^{1}} \\
\vdots & & \vdots & & \vdots \\
\frac{t_{d}^{i 1}}{t_{d}^{i}} & \cdots & \frac{t_{d}^{i j}}{t_{d}^{i}} & \cdots & \frac{t_{d}^{i m}}{t_{d}^{i}} \\
\vdots & & \vdots & & \vdots \\
\frac{t_{d}^{m 1}}{t_{d}^{m}} & \cdots & \frac{t_{d}^{m j}}{t_{d}^{m}} & \cdots & \frac{t_{d}^{m m}}{t_{d}^{m}}
\end{array}\right] \\
& =\left[\begin{array}{ccccc}
T_{d *}^{11} & \cdots & T_{d *}^{1 j} & \cdots & T_{d *}^{1 m} \\
\vdots & & \vdots & & \vdots \\
T_{d *}^{i 1} & \cdots & T_{d *}^{i j} & \cdots & T_{d *}^{i m} \\
\vdots & & \vdots & & \vdots \\
T_{d *}^{m 1} & \cdots & T_{d *}^{m j} & \cdots & T_{d *}^{m m}
\end{array}\right] .
\end{aligned}
$$

Step 6 (build the weighted supermatrix, and obtain the influential weights of elements). Multiply the normalized total criteria relation matrix $\left(T_{c^{*}}\right)$ by the normalized total dimensions relation matrix $\left(T_{d *}\right)$ to produce the original weighted supermatrix $S$, as shown in

$$
S=\left[\begin{array}{ccccc}
T_{c *}^{11} \times T_{d *}^{11} & \cdots & T_{c *}^{1 j} \times T_{d *}^{1 j} & \cdots & T_{c *}^{1 m} \times T_{d *}^{1 m} \\
\vdots & & \vdots & & \vdots \\
T_{c *}^{i 1} \times T_{d *}^{i 1} & \cdots & T_{c *}^{i j} \times T_{d *}^{i j} & \cdots & T_{c *}^{i m} \times T_{d *}^{i m} \\
\vdots & & \vdots & & \vdots \\
T_{c *}^{m 1} \times T_{d *}^{m 1} & \cdots & T_{c *}^{m j} \times T_{d *}^{m j} & \cdots & T_{c *}^{m m} \times T_{d *}^{m m}
\end{array}\right] .
$$

$S$ is further transposed to a column-stochastic supermatrix $S^{*}$, as shown in

$$
S^{*}=\left[\begin{array}{ccccc}
T_{c *}^{11} \times T_{d *}^{11} & \cdots & T_{c *}^{i 1} \times T_{d *}^{i 1} & \cdots & T_{c *}^{m 1} \times T_{d *}^{m 1} \\
\vdots & & \vdots & & \vdots \\
T_{c *}^{1 j} \times T_{d *}^{1 j} & \cdots & T_{c *}^{i j} \times T_{d *}^{i j} & \cdots & T_{c *}^{m j} \times T_{d *}^{m j} \\
\vdots & & \vdots & & \vdots \\
T_{c *}^{1 m} \times T_{d *}^{1 m} & \cdots & T_{c *}^{i m} \times T_{d *}^{i m} & \cdots & T_{c *}^{m m} \times T_{d *}^{m m}
\end{array}\right]
$$

Limit the weighted supermatrix $S^{*}$ by raising it to a sufficiently large power $\varphi$ (i.e., $\left.\lim _{\varphi \rightarrow \infty}\left(S^{*}\right)^{\varphi}\right)$ until it converges and becomes a long-term stable supermatrix. Then, the final global priority matrix (i.e., $W=\left[W_{1}, \ldots W_{j}, \ldots W_{n}\right]$ ) defines the influential weights among criteria. 
TABLE 4: Background information for survey respondent.

\begin{tabular}{|c|c|}
\hline Category/classification & Number \\
\hline \multicolumn{2}{|l|}{ Sex } \\
\hline Male & 12 \\
\hline Female & 4 \\
\hline \multicolumn{2}{|l|}{ Age } \\
\hline Between 31 and 40 years & 12 \\
\hline Between 41 and 50 years & 2 \\
\hline Older than 50 years & 2 \\
\hline \multicolumn{2}{|l|}{ Education level } \\
\hline Bachelor & 2 \\
\hline Master & 12 \\
\hline Ph.D. & 2 \\
\hline \multicolumn{2}{|l|}{ Working background } \\
\hline Academic field & 7 \\
\hline Industry field & 9 \\
\hline \multicolumn{2}{|l|}{ Position } \\
\hline Managerial & 3 \\
\hline Professional & 13 \\
\hline \multicolumn{2}{|l|}{ Years of work experience } \\
\hline Less than 3 years & 3 \\
\hline Between 7 and 9 years & 7 \\
\hline More than 10 years & 6 \\
\hline \multicolumn{2}{|c|}{ Company size (capital, in New Taiwan Dollars) } \\
\hline Less than 10 million & 1 \\
\hline Between 10 and 50 million & 10 \\
\hline More than 50 million & 5 \\
\hline
\end{tabular}

\section{Applications of the Proposed Model}

In order to explore the dynamic relationships between the personal, environmental, and behavioral factors that influence organizational value cocreation behavior, we developed a questionnaire to survey experts who have rich experiences in knowledge-intensive activities. Based on their input, we conducted a DANP analysis.

\subsection{Representativeness of the Surveyed Experts}

4.1.1. Background of Surveyed Experts. Northcutt and McCoy ([53], p. 87) suggested that a representative focus group should include 12 to 20 members who have the following desirable characteristics: (1) they are knowledgeable of, and experienced with, the research issue; (2) they have the abilities to ponder the questions and to adequately put their thoughts into words; (3) they have the motivation and time to participate in the study; (4) they are homogeneous concerning the important dimensions of distance and power; (5) they have good team spirit, and they are neither overpowering nor too timid to speak.

We followed these guidelines in assembling domain experts. Table 4 provides a summary of the background information regarding these experts.
To ensure that these experts understood the meaning of the research constructs, we conducted the survey face-toface. For additional clarity, we prepared detailed definitions and examples to present in the questionnaire. Participants were asked to make comprehensive pairwise comparisons regarding all research constructs in order to evaluate their effects and influences.

Pairwise relative comparison is an essential aspect of AHP and ANP. It allows decision makers to set priorities and make choices based on their objectives, knowledge, and experiences in a way that is consistent with their intuitive thought process [54]. With pairwise comparison, weights and priorities are not arbitrarily assigned; rather, they are derived from a set of redundant judgments. This method for deriving priorities is deemed reliable because (1) it is based on a sound mathematical foundation and (2) it has been validated through studies [54].

4.1.2. The Appropriateness of Sample Size. Denzin and Lincoln [55] proposed that, in qualitative research, the size of the sample is not as important as its appropriateness and richness. Moreover, following the principle of theoretical saturation, researchers should continue sampling respondents until the information collected achieves theoretical saturation. Theoretical saturation means that no new or relevant data emerge concerning a category, that the category is well developed, and that the linkages between categories are well established [56].

The DEMATEL approach allows for the evaluation of asymmetric influences between elements. Thus, unlike in AHP, which has a consistency index, there is no consistency indicator in DEMATEL. This problem can be overcome by calculating the errors of gap ratio (EGR), as defined below [57].

Consider EGR $=(1 / n(n-1)) \sum_{i=1}^{n} \sum_{j=1}^{n}\left(\left|a_{i j}^{p}-a_{i j}^{p-1}\right| / a_{i j}^{p}\right) \times$ $100 \%$, where $p$ denotes the number of sample and $a_{i j}^{p}$ is the average influence of $i$ criteria on $j$. The number of gap ratio elements is $n(n-1)$. When EGR is $\alpha$, the significance of the confidence interval is $(1-\alpha)$. In general, when $\alpha$ is less than $5 \%$, we have over $95 \%$ confidence, demonstrating that there is no significant difference between the evaluations of sample size $p$ and $p-1$. Consequently, it is reasonable to propose that sample size $p$ is significantly close to theoretical saturation and, thus, is an appropriate size.

Based on the data in Tables 5 and 6, EGR is found to be $4.449 \%$, representing a $95.551 \%$ confidence level. Consequently, Table 6 is used as input data for further DEMATEL calculations.

4.2. The Application of DEMATEL to Build an IRM. The DEMATEL technique is used to model influential relationships among dimensions and criteria and to establish an IRM representing these relationships.

4.2.1. Generate the Initial Direct-Relation Matrix. As shown in Table 6, the group consensus results yield matrix $A$, the initial direct-relation matrix. Matrix $A$ is normalized using (1) and (2) to produce matrix $G$, as shown in Table 7. 
TABLE 5: Group consensuses of the 15 respondents on the degree of influence among the criteria (unit: \%).

\begin{tabular}{lcccccccccc}
\hline Criteria & $a_{1}$ & $a_{2}$ & $a_{3}$ & $b_{1}$ & $b_{2}$ & $b_{3}$ & $b_{4}$ & $c_{1}$ & $c_{2}$ & $c_{3}$ \\
\hline$a_{1}$ & 0.000 & 3.200 & 3.133 & 0.333 & 1.200 & 0.333 & 0.267 & 1.733 & 2.133 & 3.133 \\
$a_{2}$ & 1.200 & 0.000 & 2.667 & 0.333 & 1.200 & 0.133 & 0.400 & 2.200 & 1.933 & 1.733 \\
$a_{3}$ & 1.067 & 2.000 & 0.000 & 0.867 & 1.533 & 1.067 & 0.733 & 2.667 & 1.667 & 2.267 \\
$b_{1}$ & 3.200 & 2.733 & 3.067 & 0.000 & 2.867 & 3.000 & 2.467 & 2.800 & 2.400 & 2.800 \\
$b_{2}$ & 2.067 & 2.467 & 2.533 & 0.400 & 0.000 & 2.467 & 0.533 & 2.133 & 2.733 & 2.867 \\
$b_{3}$ & 1.933 & 2.467 & 2.200 & 0.400 & 2.000 & 0.000 & 1.000 & 1.733 & 1.667 & 2.400 \\
$b_{4}$ & 2.400 & 2.600 & 2.733 & 0.667 & 1.600 & 3.133 & 0.000 & 2.600 & 2.067 & 2.800 \\
$c_{1}$ & 1.067 & 1.800 & 2.333 & 1.067 & 1.467 & 1.133 & 0.200 & 0.000 & 2.667 & 2.933 \\
$c_{2}$ & 1.067 & 1.467 & 1.533 & 0.533 & 1.067 & 0.467 & 0.000 & 1.067 & 0.000 & 3.333 \\
$c_{3}$ & 1.600 & 1.533 & 2.200 & 1.067 & 1.267 & 1.000 & 0.200 & 1.267 & 2.467 & 0.000 \\
\hline
\end{tabular}

TABLE 6: Group consensuses of the 16 respondents on the degree of influence among the criteria (unit: \%).

\begin{tabular}{lcccccccccc}
\hline Criteria & $a_{1}$ & $a_{2}$ & $a_{3}$ & $b_{1}$ & $b_{2}$ & $b_{3}$ & $b_{4}$ & $c_{1}$ & $c_{2}$ \\
\hline$a_{1}$ & 0.000 & 3.188 & 3.125 & 0.313 & 1.125 & 0.313 & 0.250 & 1.625 & 2.188 & 3.125 \\
$a_{2}$ & 1.125 & 0.000 & 2.750 & 0.313 & 1.125 & 0.125 & 0.375 & 2.250 & 1.938 & 1.750 \\
$a_{3}$ & 1.000 & 1.875 & 0.000 & 0.813 & 1.438 & 1.000 & 0.688 & 2.500 & 1.563 & 2.188 \\
$b_{1}$ & 3.188 & 2.688 & 3.063 & 0.000 & 2.688 & 2.938 & 2.313 & 2.625 & 2.250 & 2.813 \\
$b_{2}$ & 2.063 & 2.438 & 2.500 & 0.375 & 0.000 & 2.313 & 0.500 & 2.000 & 2.563 & 2.813 \\
$b_{3}$ & 1.938 & 2.500 & 2.188 & 0.375 & 1.875 & 0.000 & 0.938 & 1.625 & 1.563 & 2.500 \\
$b_{4}$ & 2.375 & 2.563 & 2.688 & 0.688 & 1.500 & 3.063 & 0.000 & 2.500 & 1.938 & 2.875 \\
$c_{1}$ & 1.125 & 1.875 & 2.313 & 1.000 & 1.438 & 1.063 & 0.188 & 0.000 & 2.625 \\
$c_{2}$ & 1.000 & 1.500 & 1.563 & 0.500 & 1.125 & 0.438 & 0.000 & 1.000 & 0.000 & 3.875 \\
$c_{3}$ & 1.500 & 1.438 & 2.063 & 1.000 & 1.188 & 0.938 & 0.188 & 1.188 & 2.313 & 0.000 \\
\hline
\end{tabular}

TABLE 7: Normalized initial direct-relation matrix.

\begin{tabular}{lcccccccccc}
\hline Criteria & $a_{1}$ & $a_{2}$ & $a_{3}$ & $b_{1}$ & $b_{2}$ & $b_{3}$ & $b_{4}$ & $c_{1}$ & $c_{2}$ & $c_{3}$ \\
\hline$a_{1}$ & 0.000 & 0.130 & 0.127 & 0.013 & 0.046 & 0.013 & 0.010 & 0.066 & 0.089 & 0.127 \\
$a_{2}$ & 0.046 & 0.000 & 0.112 & 0.013 & 0.046 & 0.005 & 0.015 & 0.092 & 0.079 & 0.071 \\
$a_{3}$ & 0.041 & 0.076 & 0.000 & 0.033 & 0.059 & 0.041 & 0.028 & 0.102 & 0.064 & 0.089 \\
$b_{1}$ & 0.130 & 0.109 & 0.125 & 0.000 & 0.109 & 0.120 & 0.094 & 0.107 & 0.092 & 0.115 \\
$b_{2}$ & 0.084 & 0.099 & 0.102 & 0.015 & 0.000 & 0.094 & 0.020 & 0.081 & 0.104 & 0.115 \\
$b_{3}$ & 0.079 & 0.102 & 0.089 & 0.015 & 0.076 & 0.000 & 0.038 & 0.066 & 0.064 & 0.102 \\
$b_{4}$ & 0.097 & 0.104 & 0.109 & 0.028 & 0.061 & 0.125 & 0.000 & 0.102 & 0.079 \\
$c_{1}$ & 0.046 & 0.076 & 0.094 & 0.041 & 0.059 & 0.043 & 0.008 & 0.000 & 0.107 \\
$c_{2}$ & 0.041 & 0.061 & 0.064 & 0.020 & 0.046 & 0.018 & 0.000 & 0.041 & 0.000 & 0.117 \\
$c_{3}$ & 0.061 & 0.059 & 0.084 & 0.041 & 0.048 & 0.038 & 0.008 & 0.048 & 0.094 & 0.000 \\
\hline
\end{tabular}

Then, the total criteria relation matrix and total dimensions relation matrix can be derived by (3)-(5), as shown in Tables 8 and 9.

Furthermore, the total influence given and received by each dimension and criterion can be summarized using (6), as shown in Table 10. Thus, the IRM of the DEMATEL technique can be obtained as shown in Figures 4-7.
4.3. The Application of ANP to Obtain Influential Weights of Criteria. Having determined the relationship structure of all dimensions and criteria, ANP is applied to obtain the influential weights of the criteria. First, the total criteria relation matrix and total dimensions relation matrix are normalized based on (7) and (8), as shown in Tables 11 and 12. 
TABLE 8: Total criteria relation matrix.

\begin{tabular}{lccccccccccc}
\hline Criteria & $a_{1}$ & $a_{2}$ & $a_{3}$ & $b_{1}$ & $b_{2}$ & $b_{3}$ & $b_{4}$ & $c_{1}$ & $c_{2}$ & $c_{3}$ \\
\hline$a_{1}$ & 0.074 & 0.223 & 0.237 & 0.048 & 0.115 & 0.065 & 0.033 & 0.158 & 0.192 & 0.247 & 0.533 \\
$a_{2}$ & 0.103 & 0.084 & 0.198 & 0.042 & 0.102 & 0.050 & 0.034 & 0.161 & 0.161 & 0.174 & 0.386 \\
$a_{3}$ & 0.111 & 0.168 & 0.111 & 0.064 & 0.123 & 0.091 & 0.050 & 0.180 & 0.161 & 0.204 & 0.391 \\
$b_{1}$ & 0.256 & 0.288 & 0.323 & 0.058 & 0.228 & 0.211 & 0.133 & 0.262 & 0.270 & 0.333 & 0.630 \\
$b_{2}$ & 0.168 & 0.217 & 0.235 & 0.056 & 0.086 & 0.150 & 0.048 & 0.186 & 0.223 & 0.261 & 0.339 \\
$b_{3}$ & 0.156 & 0.208 & 0.212 & 0.052 & 0.148 & 0.059 & 0.062 & 0.163 & 0.176 & 0.234 & 0.321 \\
$b_{4}$ & 0.198 & 0.245 & 0.268 & 0.074 & 0.159 & 0.192 & 0.035 & 0.225 & 0.223 & 0.290 & 0.461 \\
$c_{1}$ & 0.120 & 0.175 & 0.205 & 0.073 & 0.128 & 0.096 & 0.033 & 0.093 & 0.206 & 0.238 & 0.537 \\
$c_{2}$ & 0.094 & 0.132 & 0.146 & 0.046 & 0.095 & 0.057 & 0.018 & 0.106 & 0.079 & 0.216 & 0.401 \\
$c_{3}$ & 0.122 & 0.144 & 0.178 & 0.067 & 0.107 & 0.082 & 0.029 & 0.125 & 0.176 & 0.112 & 0.413 \\
$s_{j}$ & 0.289 & 0.475 & 0.546 & 0.239 & 0.621 & 0.612 & 0.278 & 0.323 & 0.461 & 0.566 & \\
\hline
\end{tabular}

TABLE 9: Total dimensions relation matrix.

\begin{tabular}{lcccr}
\hline Dimensions & $A$ & $B$ & $C$ & $r_{i}$ \\
\hline$A$ & 0.146 & 0.068 & 0.182 & 0.396 \\
$B$ & 0.231 & 0.109 & 0.237 & 0.578 \\
$C$ & 0.146 & 0.069 & 0.150 & 0.365 \\
$s_{j}$ & 0.523 & 0.246 & 0.569 & \\
\hline
\end{tabular}

TABLE 10: Sum of influences given and received on dimensions and criteria.

\begin{tabular}{ccccc}
\hline & $r_{i}$ & $s_{j}$ & $r_{i}+s_{j}$ & $r_{i}-s_{j}$ \\
\hline$A$ & 0.396 & 0.523 & 0.919 & -0.127 \\
$a_{1}$ & 0.533 & 0.289 & 0.822 & 0.245 \\
$a_{2}$ & 0.386 & 0.475 & 0.861 & -0.089 \\
$a_{3}$ & 0.391 & 0.546 & 0.937 & -0.156 \\
$B$ & 0.578 & 0.247 & 0.824 & 0.331 \\
$b_{1}$ & 0.630 & 0.239 & 0.869 & -0.282 \\
$b_{2}$ & 0.339 & 0.621 & 0.960 & -0.292 \\
$b_{3}$ & 0.321 & 0.612 & 0.933 & 0.183 \\
$b_{4}$ & 0.461 & 0.278 & 0.739 & -0.204 \\
$C$ & 0.365 & 0.569 & 0.935 & 0.214 \\
$c_{1}$ & 0.537 & 0.323 & 0.860 & -0.060 \\
$c_{2}$ & 0.401 & 0.461 & 0.862 & -0.154 \\
$c_{3}$ & 0.413 & 0.566 & 0.979 \\
\hline
\end{tabular}

Second, the normalized total criteria relation matrix is weighted by the normalized total dimensions matrix to obtain an original weighted supermatrix. The matrix is transposed to produce the weighted supermatrix shown in Table 13.

Finally, the influential weights of criteria can be obtained by limiting the power of the weighted supermatrix until it reaches a stable state, as shown in Table 14.

4.4. Results and Discussions. In the context of organizational value cocreation, the major results of this study can be described as follows. First, the triadic reciprocity of personal, environmental, and behavioral factors is validated. The total criteria relation matrix and total dimensions relation matrix capture the effects and influences of elements, and there are no empty cells in the matrix. Therefore, all elements influence and are influenced by all other elements. This conclusion reflects the dynamism and complexity of the real world quite well. Second, the dominant influencing trends are visually identified. Though all elements influence each other, there still exist some significant relationships, as shown in Table 15. 


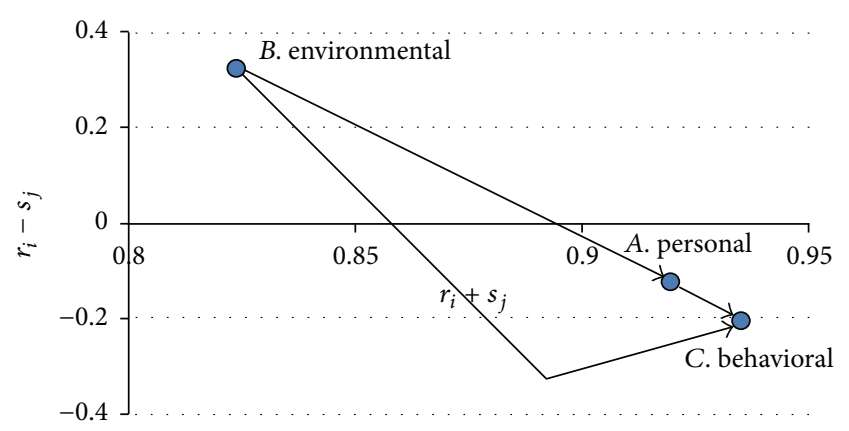

FIGURE 4: Impact-relation map of dimensions.

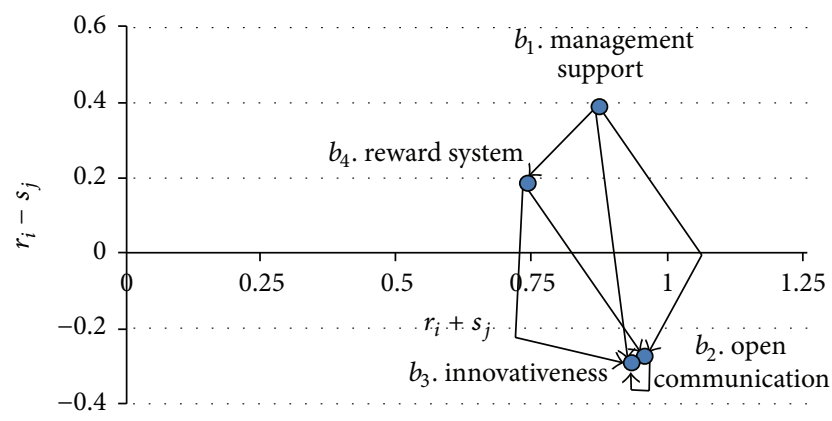

FIGURE 5: Impact-relation map of criterion $b$.

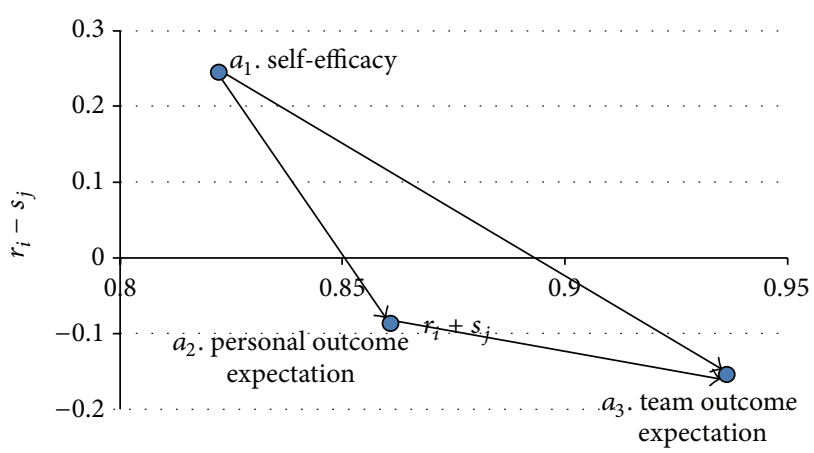

FIGURE 6: Impact-relation map of criterion $a$.

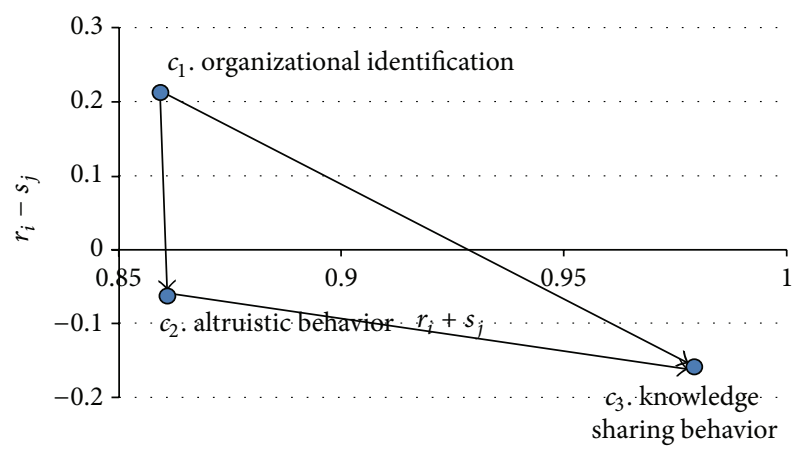

FIgURE 7: Impact-relation map of criterion $c$.
From a dimensional point of view, the environmental factors affect both the personal and behavioral factors $(B \rightarrow$ $\left.\left\{\begin{array}{ll}A & C\end{array}\right\}\right)$. Further, the personal factors affect the behavioral factors $(A \rightarrow\{C\})$. This implies that, in order to increase organizational value cocreation behavior, managers first need to improve environmental factors. Such an approach would motivate individuals to conduct the desired behaviors.

Similarly, in terms of the environmental dimension, top management support affects the reward system, innovativeness, and open communication $\left(b_{1} \rightarrow\left\{\begin{array}{lll}b_{4} & b_{2} & b_{3}\end{array}\right\}\right)$. Further, the reward system affects innovativeness and open communication $\left(b_{4} \rightarrow\left\{\begin{array}{ll}b_{2} & b_{3}\end{array}\right\}\right)$, and innovativeness affects open communication $\left(b_{2} \rightarrow\left\{b_{3}\right\}\right)$. Consequently, to encourage organizational value cocreation behavior, management should implement an effective reward system capable of motivating innovativeness and open communication among employees.

Regarding personal factors, self-efficacy affects personal outcome expectations and team outcome expectations $\left(a_{1} \rightarrow\right.$ $\left.\left\{\begin{array}{ll}a_{2} & a_{3}\end{array}\right\}\right)$. In addition, personal outcome expectations affect team outcome expectations $\left(a_{2} \rightarrow\left\{a_{3}\right\}\right)$. Thus, it is clear that self-efficacy drives personal as well as team performance.

In terms of behavioral factors, organizational identification affects altruistic behavior and knowledge-sharing behavior $\left(c_{1} \rightarrow\left\{c_{2} c_{3}\right\}\right)$. Moreover, altruistic behavior affects knowledge-sharing behavior $\left(c_{2} \rightarrow\left\{c_{3}\right\}\right)$. This result shows that organizational identification acts as a foundation for altruistic behavior in general and, specifically, for knowledgesharing behavior.

Third, the influential weights of criteria are clearly identified. As shown in Table 14, the highest relative weights are found mainly in the behavioral dimension, such as knowledge-sharing behavior $\left(c_{3}\right.$, assessed at 0.158$)$, altruistic behavior $\left(c_{2}, 0.131\right)$, and organizational identification $\left(c_{1}\right.$, $0.115)$. This indicates that all domain experts gave high priority to the behaviors related to knowledge sharing. The secondmost-important dimension is personal factors, stressing the important role of team outcome expectations $\left(a_{3}, 0.145\right)$ and personal outcome expectations $\left(a_{2}, 0.127\right)$. Moreover, the results show that open communication $\left(b_{2}, 0.090\right)$ is the most critical environmental factor for knowledge sharing.

\section{Conclusion}

In the era of the knowledge economy, the importance of organizational value cocreation behavior, especially knowledge sharing, cannot be overemphasized. In fact, knowledge is of limited value if it is not updated and shared [58]. Traditional research has used large sample surveys to validate hypotheses that generally emphasize the antecedents of organizational value cocreation behavior. Instead, this study applies an MCDM approach with the following features.

First, this study utilizes social cognitive theory in its investigation of organizational value cocreation behavior. To be consistent with real-world cases, where all factors interrelate and influence each other, this study did not assume any previously hypothesized relationships in terms of direction and degree. In this regard, the findings of this 
TABLE 11: Normalized total criteria relation matrix.

\begin{tabular}{lcccccccccc}
\hline Criteria & $a_{1}$ & $a_{2}$ & $a_{3}$ & $b_{1}$ & $b_{2}$ & $b_{3}$ & $b_{4}$ & $c_{1}$ & $c_{2}$ & $c_{3}$ \\
\hline$a_{1}$ & 0.139 & 0.417 & 0.444 & 0.185 & 0.440 & 0.248 & 0.128 & 0.264 & 0.321 & 0.414 \\
$a_{2}$ & 0.268 & 0.218 & 0.514 & 0.184 & 0.447 & 0.221 & 0.148 & 0.324 & 0.325 & 0.351 \\
$a_{3}$ & 0.284 & 0.431 & 0.285 & 0.195 & 0.374 & 0.279 & 0.152 & 0.331 & 0.295 & 0.375 \\
$b_{1}$ & 0.295 & 0.332 & 0.373 & 0.092 & 0.362 & 0.336 & 0.211 & 0.303 & 0.312 & 0.385 \\
$b_{2}$ & 0.271 & 0.350 & 0.379 & 0.164 & 0.252 & 0.442 & 0.142 & 0.277 & 0.333 & 0.390 \\
$b_{3}$ & 0.271 & 0.361 & 0.368 & 0.161 & 0.463 & 0.183 & 0.194 & 0.285 & 0.306 & 0.409 \\
$b_{4}$ & 0.278 & 0.345 & 0.377 & 0.161 & 0.346 & 0.417 & 0.075 & 0.305 & 0.302 & 0.393 \\
$c_{1}$ & 0.240 & 0.350 & 0.410 & 0.222 & 0.388 & 0.290 & 0.100 & 0.173 & 0.383 & 0.444 \\
$c_{2}$ & 0.253 & 0.355 & 0.392 & 0.212 & 0.443 & 0.262 & 0.083 & 0.264 & 0.197 & 0.539 \\
$c_{3}$ & 0.274 & 0.325 & 0.401 & 0.234 & 0.375 & 0.288 & 0.103 & 0.302 & 0.427 & 0.271 \\
\hline
\end{tabular}

TABLE 12: Normalized total dimensions matrix.

\begin{tabular}{lccr}
\hline Dimensions & $A$ & $B$ & $C$ \\
\hline$A$ & 0.348 & 0.217 & 0.435 \\
$B$ & 0.376 & 0.237 & 0.386 \\
$C$ & 0.376 & 0.238 & 0.386 \\
\hline
\end{tabular}

TABLE 13: The weighted supermatrix.

\begin{tabular}{lcccccccccc}
\hline Criteria & $a_{1}$ & $a_{2}$ & $a_{3}$ & $b_{1}$ & $b_{2}$ & $b_{3}$ & $b_{4}$ & $c_{1}$ & $c_{2}$ \\
\hline$a_{1}$ & 0.048 & 0.093 & 0.099 & 0.111 & 0.102 & 0.102 & 0.105 & 0.090 & 0.095 & 0.103 \\
$a_{2}$ & 0.145 & 0.076 & 0.150 & 0.125 & 0.132 & 0.136 & 0.130 & 0.132 & 0.134 & 0.122 \\
$a_{3}$ & 0.154 & 0.179 & 0.099 & 0.140 & 0.143 & 0.139 & 0.142 & 0.154 & 0.148 & 0.151 \\
$b_{1}$ & 0.040 & 0.040 & 0.042 & 0.022 & 0.039 & 0.038 & 0.038 & 0.053 & 0.050 & 0.056 \\
$b_{2}$ & 0.096 & 0.097 & 0.081 & 0.086 & 0.060 & 0.110 & 0.082 & 0.092 & 0.105 & 0.089 \\
$b_{3}$ & 0.054 & 0.048 & 0.061 & 0.080 & 0.105 & 0.043 & 0.099 & 0.069 & 0.062 & 0.068 \\
$b_{4}$ & 0.028 & 0.032 & 0.033 & 0.050 & 0.034 & 0.046 & 0.018 & 0.024 & 0.020 & 0.025 \\
$c_{1}$ & 0.115 & 0.141 & 0.144 & 0.117 & 0.107 & 0.110 & 0.118 & 0.067 & 0.102 & 0.117 \\
$c_{2}$ & 0.140 & 0.141 & 0.128 & 0.120 & 0.129 & 0.118 & 0.117 & 0.148 & 0.076 & 0.165 \\
$c_{3}$ & 0.180 & 0.153 & 0.163 & 0.149 & 0.151 & 0.158 & 0.152 & 0.171 & 0.208 & 0.104 \\
\hline
\end{tabular}

TABLE 14: The limited supermatrix.

\begin{tabular}{lcccccccccc}
\hline Criteria & $a_{1}$ & $a_{2}$ & $a_{3}$ & $b_{1}$ & $b_{2}$ & $b_{3}$ & $b_{4}$ & $c_{1}$ & $c_{2}$ \\
\hline$a_{1}$ & 0.094 & 0.094 & 0.094 & 0.094 & 0.094 & 0.094 & 0.094 & 0.094 & 0.094 & 0.094 \\
$a_{2}$ & $\mathbf{0 . 1 2 7}$ & 0.127 & 0.127 & 0.127 & 0.127 & 0.127 & 0.127 & 0.127 & 0.127 & 0.127 \\
$a_{3}$ & $\mathbf{0 . 1 4 5}$ & 0.145 & 0.145 & 0.145 & 0.145 & 0.145 & 0.145 & 0.145 & 0.145 & 0.145 \\
$b_{1}$ & 0.045 & 0.045 & 0.045 & 0.045 & 0.045 & 0.045 & 0.045 & 0.045 & 0.045 & 0.045 \\
$b_{2}$ & $\mathbf{0 . 0 9 0}$ & 0.090 & 0.090 & 0.090 & 0.090 & 0.090 & 0.090 & 0.090 & 0.090 & 0.090 \\
$b_{3}$ & 0.066 & 0.066 & 0.066 & 0.066 & 0.066 & 0.066 & 0.066 & 0.066 & 0.066 & 0.066 \\
$b_{4}$ & 0.029 & 0.029 & 0.029 & 0.029 & 0.029 & 0.029 & 0.029 & 0.029 & 0.029 & 0.029 \\
$c_{1}$ & $\mathbf{0 . 1 1 5}$ & 0.115 & 0.115 & 0.115 & 0.115 & 0.115 & 0.115 & 0.115 & 0.115 & 0.115 \\
$c_{2}$ & $\mathbf{0 . 1 3 1}$ & 0.131 & 0.131 & 0.131 & 0.131 & 0.131 & 0.131 & 0.131 & 0.131 & 0.131 \\
$c_{3}$ & $\mathbf{0 . 1 5 8}$ & 0.158 & 0.158 & 0.158 & 0.158 & 0.158 & 0.158 & 0.158 & 0.158 & 0.158 \\
\hline
\end{tabular}


TABLE 15: Dominant influences.

\begin{tabular}{|c|c|c|}
\hline Elements \Influences & Primary & Secondary \\
\hline Dimensions & Environmental $(B)$ & $\begin{array}{l}\text { Personal }(A) \\
\text { Behavioral }(C)\end{array}$ \\
\hline $\begin{array}{l}\text { Environmental } \\
(B)^{\prime} \text { criteria }\end{array}$ & $\begin{array}{l}\text { Top management } \\
\text { support }\left(b_{1}\right)\end{array}$ & $\begin{array}{l}\text { Reward system }\left(b_{4}\right) \\
\text { Open communication } \\
\left(b_{2}\right) \\
\text { Innovativeness }\left(b_{3}\right)\end{array}$ \\
\hline $\begin{array}{l}\text { Personal }(A)^{\prime} \\
\text { criteria }\end{array}$ & Self-efficacy $\left(a_{1}\right)$ & $\begin{array}{l}\text { Personal outcome } \\
\text { expectation }\left(a_{2}\right) \\
\text { Team outcome } \\
\text { expectation }\left(a_{3}\right)\end{array}$ \\
\hline $\begin{array}{l}\text { Behavioral } \\
(C)^{\prime} \text { criteria }\end{array}$ & $\begin{array}{l}\text { Organizational } \\
\text { identification }\left(c_{1}\right)\end{array}$ & $\begin{array}{l}\text { Altruistic behavior } \\
\left(c_{2}\right) \\
\text { Knowledge sharing } \\
\text { behavior }\left(c_{3}\right)\end{array}$ \\
\hline
\end{tabular}

study provide insightful and complementary contributions to related studies.

Second, the subjects interviewed are domain experts who have rich experience with organizational value cocreation behavior. Therefore, the responses reflect their accumulated experience, rather than judgments about specific organizations. Furthermore, respondents were screened for qualifications according to suggestions for qualitative research. In addition, the number of interviewees was determined by the principle of theoretical saturation. It is significant that the final consensuses of these experts were derived by objective mathematical calculations, not subjective judgments. In this way, the results of this study can be expected to have satisfactory reliability and validity.

According to the IRMs derived from this study, the environmental dimension affects both the personal dimension and the behavioral dimension. Liebowitz [59] noted that organizations must shape and support a knowledgesharing culture in order to promote knowledge management. Zárraga and Bonache [60] and Bock et al. [11] remarked that a comfortable organizational climate may encourage individuals to share personal knowledge or to create new knowledge.

In the environmental dimension, management support is needed to establish an appropriate reward system that promotes a positive organization climate characterized by open communication and innovativeness-values that are conducive to organizational value cocreation behavior. In fact, many scholars have mentioned that supervisor or leader support is a crucial factor in successful knowledge management $[11,59,61]$. Fullan [62] noted that leadership behavior plays an important role in guiding knowledge-sharing behavior. Under this supportive environment, employees establish their personal as well as team outcome expectations according to their self-efficacies. These outcome expectations enhance their organizational identification, which further motivates their altruistic, especially knowledge-sharing, behaviors.

Cabrera et al. [63] found that personal characteristics also influence members' willingness to share knowledge.
Cabrera and Cabrera [3] pointed out that if team members have a higher degree of recognition for the team, the team members are more willing to share knowledge. Bock et al. [11] referred to the influence of self-efficacy on individuals' willingness to share knowledge. Staff members with a high level of self-efficacy are more likely to engage in knowledgesharing behaviors. Moreover, Hsu et al. [38] pointed out that individuals who share their knowledge and have a high level of self-efficacy and positive outcome expectations will influence their community members to engage in knowledgesharing behavior.

In our analysis of the factors influencing organizational value cocreation behavior, knowledge-sharing behavior is found to be the most significant, followed by outcome expectations. Furthermore, open communication is found to be the most vital factor in creating a supportive environment.

This study applies MCDM to explore the triple reciprocity of value cocreation behavior. As a result, the findings of this study are expected to provide insightful and complementary contributions to related studies. Our results may be useful in guiding the effective promotion of organizational value cocreation behavior, allowing organizations to leverage operant resources to their maximum potential.

This study utilized the DANP method to quantify the complex relationships between factors. This allowed respondents to prioritize criteria, improving the overall structure of the problem. Nevertheless, there are shortcomings of this study that can also provide directions for future related studies. First, we employed evaluation criteria that were derived from previous studies. There are some criteria that are not taken into account, such as trust and organizational citizenship. We suggest that future research include these criteria for further analysis. Second, organizational cocreation behavior may have differences within different programs. Therefore, case studies can be conducted to shed further light on this issue. In addition, future research can use other MCDM tools, such as VIKOR, to further explore tactics for motivating organization value cocreation behaviors at specific organizations.

\section{Conflict of Interests}

The authors declare that there is no conflict of interests regarding the publication of this paper.

\section{Acknowledgment}

The authors would like to thank the National Science Council (Ministry of Science and Technology) of Taiwan for partially financially supporting this research under Contract no. MOST 103-2221-E-146-003-MY2.

\section{References}

[1] R. F. Lusch, S. L. Vargo, and M. O’Brien, "Competing through service: insights from service-dominant logic," Journal of Retailing, vol. 83, no. 1, pp. 5-18, 2007. 
[2] R. F. Lusch, S. L. Vargo, and G. Wessels, "Toward a conceptual foundation for service science: contributions from servicedominant logic," IBM Systems Journal, vol. 47, no. 1, pp. 5-14, 2008.

[3] E. F. Cabrera and A. Cabrera, "Fostering knowledge sharing through people management practices," The International Journal of Human Resource Management, vol. 16, no. 5, pp. 720-735, 2005.

[4] T. H. Davenport and L. Prusak, Working Knowledge: How Organizations Manage What They Know, Harvard Business Press, 2000.

[5] N. J. Foss and T. Pedersen, "Transferring knowledge in MNCs: the role of sources of subsidiary knowledge and organizational context," Journal of International Management, vol. 8, no. 1, pp. 49-67, 2002.

[6] P. Babcock, "Shedding light on knowledge management," $H R$ Magazine, vol. 49, no. 5, pp. 46-51, 2004.

[7] R. P. Bostrom and J. S. Heinen, "MIS Problems and failures: a socio-technical perspective. Part I: the causes," MIS Quarterly, vol. 1, no. 3, pp. 17-32, 1977.

[8] D. Compeau, C. A. Higgins, and S. Huff, "Social cognitive theory and individual reactions to computing technology: a longitudinal study," MIS Quarterly: Management Information Systems, vol. 23, no. 2, pp. 145-158, 1999.

[9] R. Wood and A. Bandura, "Social cognitive theory of organizational management," Academy of Management Review, vol. 14, no. 3, pp. 361-384, 1989.

[10] A. Bandura, Social Foundations of Thought and Action: A Social Cognitive Theory, Prentice Hall, Englewood Cliffs, NJ, USA, 1986.

[11] G.-W. Bock, R. W. Zmud, Y.-G. Kim, and J.-N. Lee, "Behavioral intention formation in knowledge sharing: examining the roles of extrinsic motivators, social-psychological forces, and organizational climate," MIS Quarterly: Management Information Systems, vol. 29, no. 1, pp. 87-111, 2005.

[12] D. W. Organ, Organizational Citizenship Behavior: The Good Soldier Syndrome, Lexington Books/DC Heath and Company, 1988.

[13] D. W. Organ and M. Konovsky, "Cognitive versus affective determinants of organizational citizenship behavior," Journal of Applied Psychology, vol. 74, no. 1, pp. 157-164, 1989.

[14] L. J. Williams and S. E. Anderson, "Job satisfaction and organizational commitment as predictors of organizational citizenship and in-role behaviors," Journal of Management, vol. 17, no. 3, pp. 601-617, 1991.

[15] K. Lee and N. J. Allen, "Organizational citizenship behavior and workplace deviance: the role of affect and cognitions," Journal of Applied Psychology, vol. 87, no. 1, pp. 131-142, 2002.

[16] P. M. Podsakoff, S. B. MacKenzie, J. B. Paine, and D. G. Bachrach, "Organizational citizenship behaviors: a critical review of the theoretical and empirical literature and suggestions for future research," Journal of Management, vol. 26, no. 3 , pp. 513-563, 2000.

[17] D. R. Denison, "What is the difference between organizational culture and organizational climate? A native's point of view on a decade of paradigm wars," Academy of Management Review, vol. 21, no. 3, pp. 619-654, 1996.

[18] G. Christou, "A comparison between experienced and inexperienced video game players' perceptions," Human-Centric Computing and Information Sciences, vol. 3, article 15, 2013.
[19] N. Kaya, E. Koc, and D. Topcu, "An exploratory analysis of the influence of human resource management activities and organizational climate on job satisfaction in Turkish banks," The International Journal of Human Resource Management, vol. 21, no. 11, pp. 2031-2051, 2010.

[20] G. H. Litwin and R. A. Stringer Jr., Motivation and Organizational Climate, Harvard University Press, 1968.

[21] M. Schulte, C. Ostroff, S. Shmulyian, and A. Kinicki, "Organizational climate configurations: relationships to collective attitudes, customer satisfaction, and financial performance," Journal of Applied Psychology, vol. 94, no. 3, pp. 618-634, 2009.

[22] G.-W. Bock and Y.-G. Kim, "Breaking the myths of rewards: an exploratory study of attitudes about knowledge sharing," Information Management Resources Journal, vol. 15, no. 2, pp. 14-21, 2002.

[23] C. E. Connelly and E. K. Kelloway, "Predictors of employees' perceptions of knowledge sharing cultures," Leadership \& Organization Development Journal, vol. 24, no. 5, pp. 294-301, 2003.

[24] W. A. Taylor and G. H. Wright, "Organizational readiness for successful knowledge sharing: challenges for public sector managers," Information Resources Management Journal, vol. 17, no. 2, pp. 22-37, 2004.

[25] P. J. Hinds and J. Pfeffer, "Why organizations don't 'know what they know': cognitive and motivational factors affecting the transfer of expertise," in Sharing Expertise: Beyond Knowledge Management, pp. 3-26, 2003.

[26] S. L. Jarvenpaa and D. S. Staples, "The use of collaborative electronic media for information sharing: an exploratory study of determinants," The Journal of Strategic Information Systems, vol. 9, no. 2-3, pp. 129-154, 2000.

[27] S.-Y. Choi and J.-M. Kang, "An adaptive system supporting collaborative learning based on a location-based social network and semantic user modeling," International Journal of Distributed Sensor Networks, vol. 2012, Article ID 506810, 9 pages, 2012.

[28] H.-J. Kim, R. D. Caytiles, and T.-H. Kim, "Design of an effective WSN-based interactive u-learning model," International Journal of Distributed Sensor Networks, vol. 2012, Article ID 514836, 12 pages, 2012.

[29] K. M. Bartol and A. Srivastava, "Encouraging knowledge sharing: the role of organizational reward systems," Journal of Leadership \& Organizational Studies, vol. 9, no. 1, pp. 64-76, 2002.

[30] H.-F. Lin and G.-G. Lee, "Effects of socio-technical factors on organizational intention to encourage knowledge sharing," Management Decision, vol. 44, no. 1, pp. 74-88, 2006.

[31] G. F. Templeton, B. R. Lewis, and C. A. Snyder, "Development of a measure for the organizational learning construct," Journal of Management Information Systems, vol. 19, no. 2, pp. 175-218, 2002.

[32] A. Bandura, "Self-efficacy mechanism in human agency," American Psychologist, vol. 37, no. 2, pp. 122-147, 1982.

[33] A. Bandura, Self-Efficacy: The Exercise of Self-Control, W. H. Freeman and Company, Gordonsville, Va, USA, 1997.

[34] J. E. Ormrod, Essentials of Educational Psychology, Pearson Merrill, Prentice Hall, 2006.

[35] M. M. Wasko and S. Faraj, "Why should I share? Examining social capital and knowledge contribution in electronic networks of practice," MIS Quarterly: Management Information Systems, vol. 29, no. 1, pp. 35-57, 2005. 
[36] M. Igbaria and J. Iivari, "The effects of self-efficacy on computer usage," Omega, vol. 23, no. 6, pp. 587-605, 1995.

[37] T. Saba, "Implications of E-learning systems and self-efficiency on students outcomes: a model approach," Human-Centric Computing and Information Sciences, vol. 2, no. 1, article 6, 2012.

[38] M.-H. Hsu, T. L. Ju, C.-H. Yen, and C.-M. Chang, "Knowledge sharing behavior in virtual communities: the relationship between trust, self-efficacy, and outcome expectations," International Journal of Human Computer Studies, vol. 65, no. 2, pp. 153-169, 2007.

[39] T.-C. Lin and C.-C. Huang, "Understanding knowledge management system usage antecedents: an integration of social cognitive theory and task technology fit," Information and Management, vol. 45, no. 6, pp. 410-417, 2008.

[40] A. Gabus and E. Fontela, World Problems: An Invitation to Further Thought within the Framework of DEMATEL, Battelle Geneva Research Center, Geneva, Switzerland, 1972.

[41] J.-I. Shieh, H.-H. Wu, and K.-K. Huang, "A DEMATEL method in identifying key success factors of hospital service quality," Knowledge-Based Systems, vol. 23, no. 3, pp. 277-282, 2010.

[42] J.-K. Chen and I.-S. Chen, "Using a novel conjunctive MCDM approach based on DEMATEL, fuzzy ANP, and TOPSIS as an innovation support system for Taiwanese higher education," Expert Systems with Applications, vol. 37, no. 3, pp. 1981-1990, 2010.

[43] G.-H. Tzeng, C.-H. Chiang, and C.-W. Li, "Evaluating intertwined effects in e-learning programs: a novel hybrid MCDM model based on factor analysis and DEMATEL," Expert Systems with Applications, vol. 32, no. 4, pp. 1028-1044, 2007.

[44] W.-R. Jerry Ho, C.-L. Tsai, G.-H. Tzeng, and S.-K. Fang, "Combined DEMATEL technique with a novel MCDM model for exploring portfolio selection based on CAPM," Expert Systems with Applications, vol. 38, no. 1, pp. 16-25, 2011.

[45] B. Chang, C.-W. Chang, and C.-H. Wu, "Fuzzy DEMATEL method for developing supplier selection criteria," Expert Systems with Applications, vol. 38, no. 3, pp. 1850-1858, 2011.

[46] W.-W. Wu, "Choosing knowledge management strategies by using a combined ANP and DEMATEL approach," Expert Systems with Applications, vol. 35, no. 3, pp. 828-835, 2008.

[47] W.-W. Wu and Y.-T. Lee, "Developing global managers' competencies using the fuzzy DEMATEL method," Expert Systems with Applications, vol. 32, no. 2, pp. 499-507, 2007.

[48] Y.-C. Lee, M.-L. Li, T.-M. Yen, and T.-H. Huang, "Analysis of adopting an integrated decision making trial and evaluation laboratory on a technology acceptance model," Expert Systems with Applications, vol. 37, no. 2, pp. 1745-1754, 2010.

[49] T. L. Saaty, The Analytic Network Process: Decision Making with Dependence and Feedback: The Organization and Prioritization of Complexity, RWS Publications, 1996.

[50] H.-Y. Jeong, J. H. Park, and Y.-S. Jeong, "An ANP-based practical quality model for a secure embedded system with sensor network," International Journal of Distributed Sensor Networks, vol. 2014, Article ID 505242, 7 pages, 2014.

[51] F.-H. Chen, T.-S. Hsu, and G.-H. Tzeng, "A balanced scorecard approach to establish a performance evaluation and relationship model for hot spring hotels based on a hybrid MCDM model combining DEMATEL and ANP," International Journal of Hospitality Management, vol. 30, no. 4, pp. 908-932, 2011.

[52] Y.-H. Hung, T.-L. Huang, J.-C. Hsieh, H.-J. Tsuei, C.-C. Cheng, and G.-H. Tzeng, "Online reputation management for improving marketing by using a hybrid MCDM model," KnowledgeBased Systems, vol. 35, pp. 87-93, 2012.
[53] N. Northcutt and D. McCoy, Interactive Qualitative Analysis: A Systems Method For Qualitative Research, Sage, Thousand Oaks, Calif, USA, 2004.

[54] R. F. Dyer and E. H. Forman, An Analytic Approach to Marketing Decisions, Prentice Hall, Englewood Cliffs, NJ, USA, 1991.

[55] N. K. Denzin and Y. S. Lincoln, The Landscape of Qualitative Research: Theories and Issues, Sage, 1998.

[56] A. Strauss and J. Corbin, Basics of Qualitative Research: Techniques and Procedures for Developing Grounded Theory, 2007.

[57] W.-Y. Chiu, G.-H. Tzeng, and H.-L. Li, "Improving the estore business model for satisfying customers' needs using a hybrid MCDM combined DANP with grey relational model," in Advances in Intelligent Decision Technologies, vol. 4 of Smart Innovation, Systems and Technologies, pp. 113-121, Springer, Berlin, Germany, 2010.

[58] E. Turban, J. K. Lee, D. King, T. P. Liang, and D. Turban, Electronic Commerce 2012, Prentice Hall Press, New York, NY, USA, 2011.

[59] J. Liebowitz, "A knowledge management strategy for the Jason Organization: a case study," Journal of Computer Information Systems, vol. 44, no. 2, pp. 1-5, 2003.

[60] C. Zárraga and J. Bonache, "Assessing the team environment for knowledge sharing: an empirical analysis," International Journal of Human Resource Management, vol. 14, no. 7, pp. 1227-1245, 2003.

[61] S. C. Voelpel, M. Dous, and T. H. Davenport, "Five steps to creating a global knowledge-sharing system: Siemens' ShareNet," Academy of Management Executive, vol. 19, no. 2, pp. 9-23, 2005.

[62] M. Fullan, "The role of leadership in the promotion of knowledge management in schools," Teachers \& Teaching, vol. 8, no. 3-4, pp. 409-419, 2002.

[63] Á. Cabrera, W. C. Collins, and J. F. Salgado, "Determinants of individual engagement in knowledge sharing," International Journal of Human Resource Management, vol. 17, no. 2, pp. 245264, 2006.

[64] S.-S. Chen, Y.-W. Chuang, and P.-Y. Chen, "Behavioral intention formation in knowledge sharing: examining the roles of KMS quality, KMS self-efficacy, and organizational climate," Knowledge-Based Systems, vol. 31, pp. 106-118, 2012.

[65] C.-P. Yu and T.-H. Chu, "Exploring knowledge contribution from an OCB perspective," Information \& Management, vol. 44, no. 3, pp. 321-331, 2007. 


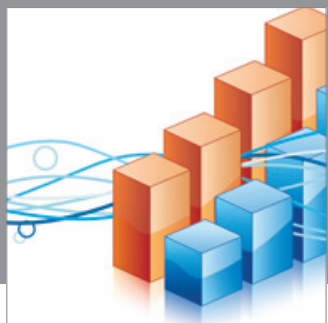

Advances in

Operations Research

mansans

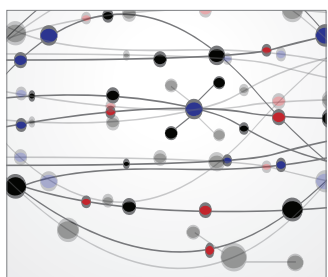

The Scientific World Journal
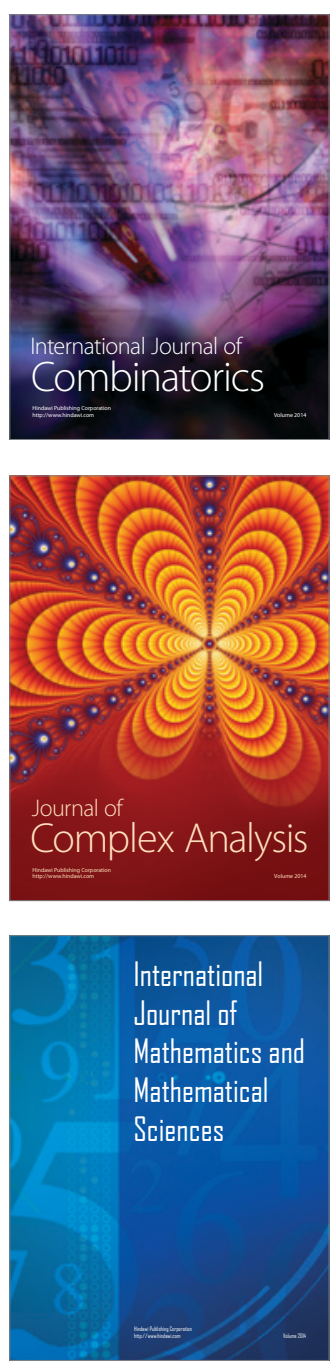
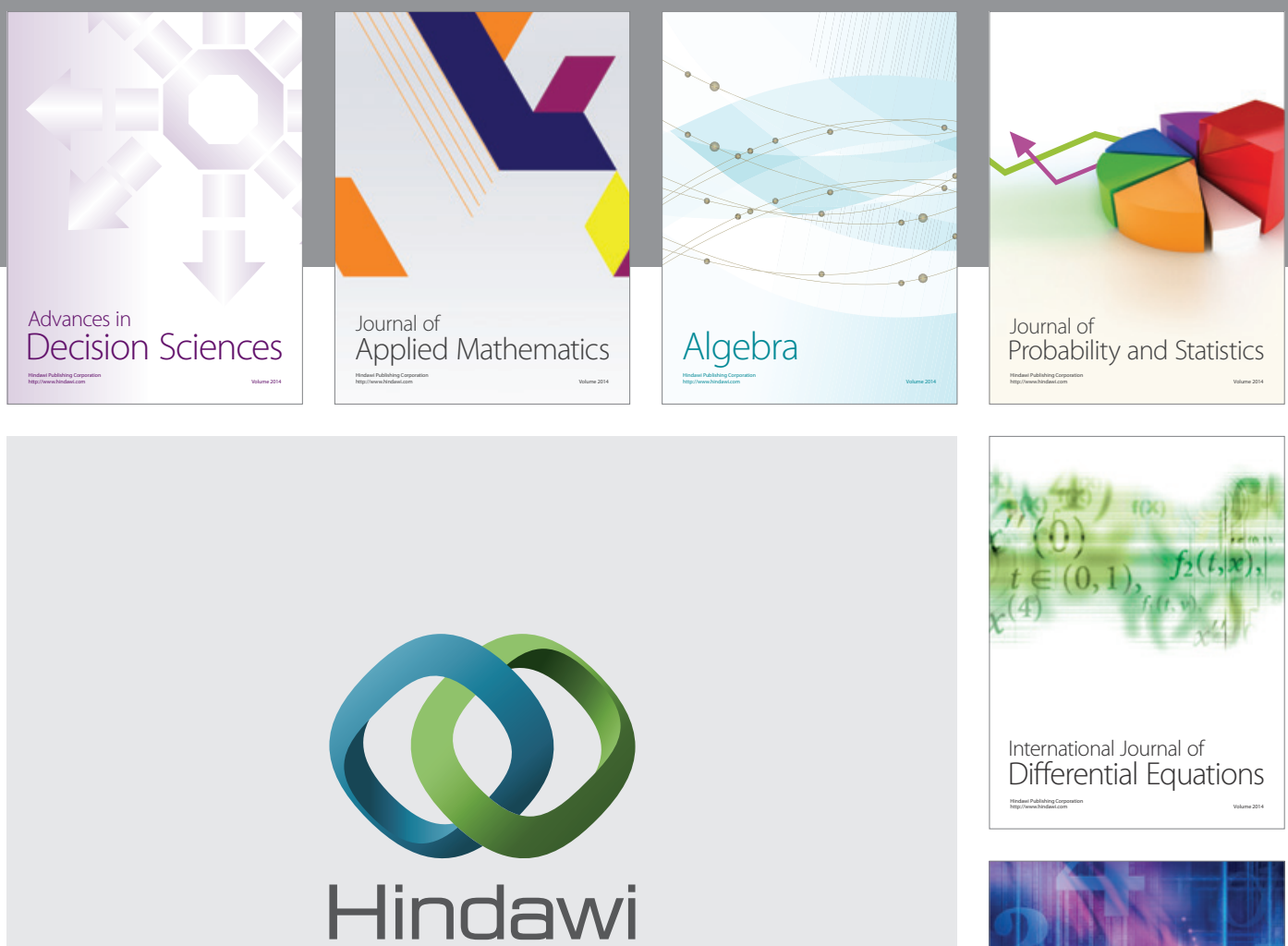

Submit your manuscripts at http://www.hindawi.com
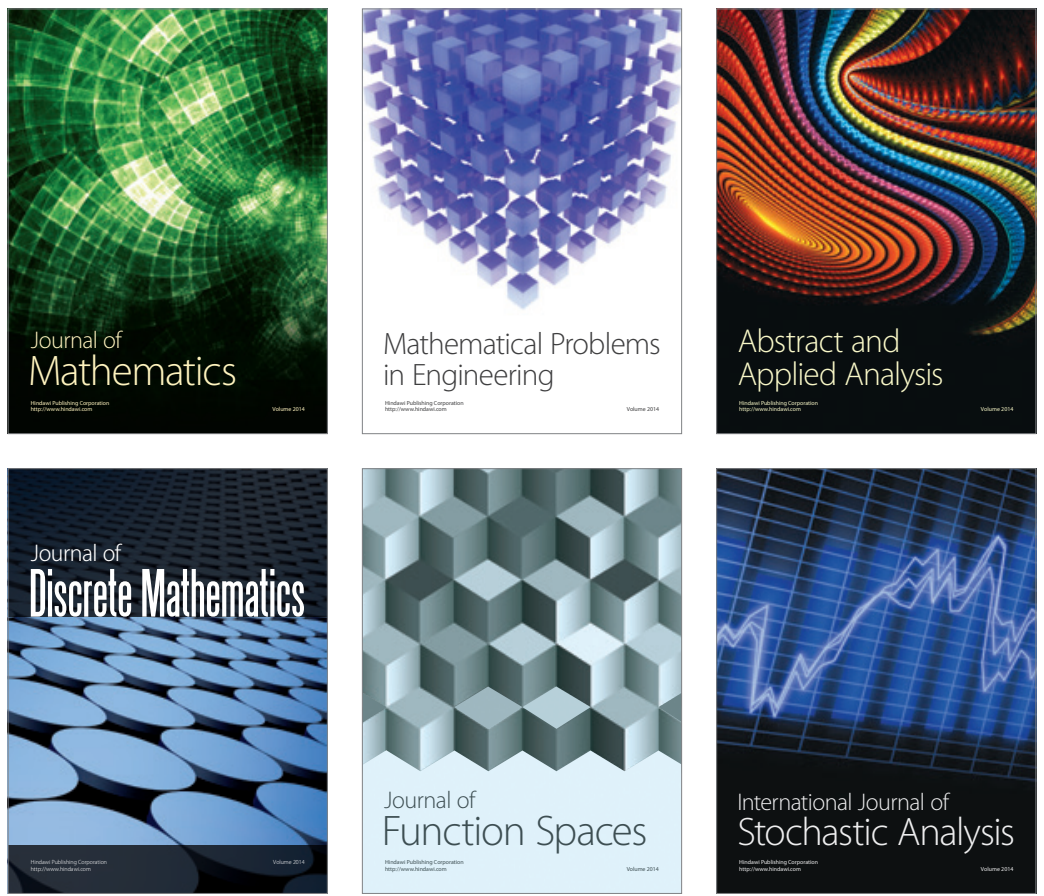

Journal of

Function Spaces

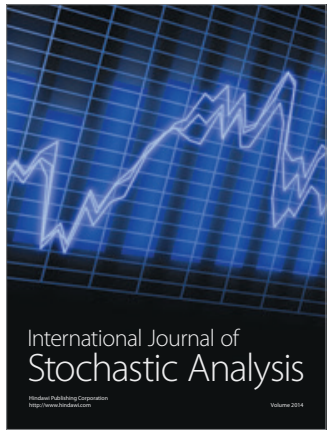

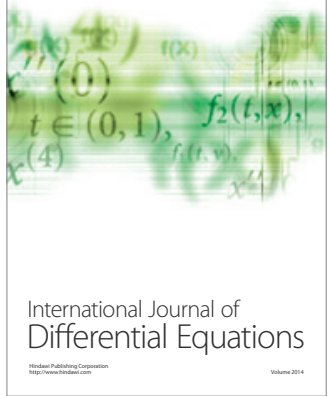
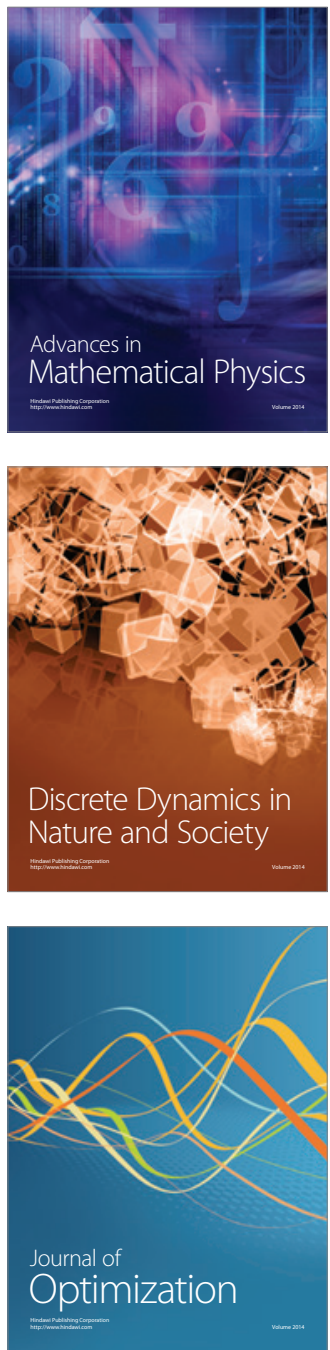